hops for the machine remains the responsibility of the hop grower.

The correct interpretation of the results of all this work demands more knowledge of how the hop plant grows than is at present available. It is hoped that it may soon be found possible to appoint a plant physiologist at Wye College to make a detailed study of the pattern of growth of the hop plant.

\section{THE HANDICAPPED CHILD}

TN a school population of approximately $5,970,000$ 1 in England and Wales, 16,719 were pupils known to school medical officers to be physically handicapped. The most frequently recorded conditions responsible for the handicap included heart disease $(4,453)$, cerebral palsy (2,954), deformities and amputations of the limbs $(2,053)$, poliomyelitis $(2,001)$, tuberculosis $(1,766)$ and spina bifida $(543)$. It is estimated that only about one child in every thousand is too severely handicapped to become entirely selfsupporting and to be able to live a full life. The increasing emphasis of recent years upon the advisability of keeping such children at home has added considerably to the responsibility involved in the care of these children. It is not only in the case of the deaf child that there is often more than one patient. Indeed, there are often three, for both parents as well as the child have to be considered. No handicapped child can achieve the optimum enjoyment of life unless the parents are prepared to carry out to the full the instructions of their medical advisers.

The family doctor's responsibility in dealing with these unfortunate children is threefold. In the first place he must be on the look-out for any handicap so that he can detect it at the earliest possible age and refer the child to a specialist for advice as to what can be done to overcome, or at least ameliorate, the disability. Secondly, he must know of the organizations, voluntary and statutory, which are available to help such children. Thirdly, there is the supervision and care of the child in the home.

All these aspects are dealt with in a remarkably good issue of The Practitioner (174, No. 1042; April 1955), which includes articles by specialists on children's disabilities.

\section{BREEDING BEHAVIOUR OF THE AMERICAN COOT}

COME peculiarities in the breeding behaviour of $S$ the American coot (Fulica americans) have been described by G. W. Gullion (Auk, 71 ; October 1954).

The bird is probably always monogamous in its sexual behaviour. If one mate disappears during the nesting season, a second mate may be accepted within forty-eight hours. Among the resident coots with secure territories, pairing seems to be as permanent as the life of the birds or their ability to maintain a territory.

Coots breed in a habitat which contains abundant nesting material, and they use this material freely in constructing floating structures associated with breeding. These structures are bulky, and since materials seldom present a procurement problem, they are not built for permanence but must be added to repeatedly while in use. Eggs are seldom laid in more than two of the eight or nine structures which are usually built. The other structures are utilized for resting, roosting and brooding sites.

Three types of structures built by coots-a display platform, the egg nest and a brood nest-follow one another in a definite sequence, and breeding events can be reliably predicted by their appearance. Certain modes of construction permit the identifica. tion of a nest type even before it is placed in use.

Copulation normally, perhaps always, takes place on a display platform. There is little or no precopulatory display or chase, and the two birds resume normal activity within two or three minutes following copulation. Eggs may appear before the nest is completed and are laid daily in the very early hours of the morning. The nest is completed and lined by the time the clutch is complete.

Incubation is continuous and is shared by both sexes, the male probably doing the greater share of it.

When deposition of the clutch is just beginning the female incubates all night, but otherwise the male incubates from dusk to dawn; the female always takes about a four-hour shift at dawn and then shifts of about one-hour duration follow until sunset. Young coots are quite helpless until a day or so old and require prolonged parental care. The male parent does most of the brooding during the staggered hatching period, while the female brings food to the nestlings and takes the older ones away to feed and brood. Later, the parents divide the brood during feeding and brooding.

\section{CHLOROPLAST STRUCTURE}

$\mathrm{T}$ a study of the structure and swelling properties 1 of the chloroplasts of Nitella cristata, F. V. Mercer, A. J. Hodge, A. B. Hope and J. D. McLean have made some new and interesting observations and stated some tentative conclusions (Austral. J. Biol. Sci., 8, 1, 1; 1955). Electron-microscope studies of ultra-thin sections have shown that the normal chloroplast consists of about 40-100 lamellæc.70 A. apart, enclosed by an external membrane c. $70 \mathrm{~A}$. thickness. Grana do not occur. The space within the chloroplast not occupied by the lamellæ is filled with a granular material resembling the cytoplasm. The chloroplast often contains a considerable number of osmiophilic globules c. $0 \cdot 1 \mu$ in diameter lying between the lamellæ, their staining reaction with osmic acid indicating that they are probably lipoidal.

Numerous small osmiophilic bodies c. $100 \mathrm{~A}$. or less in diameter are associated with the lamellæ. Starch grains, when present, occur between the lamellæ and appear to be enclosed within by a membrane. During swelling in hypotonic solutions, chloroplasts change in shape from disk to sphere to cylinder. Swelling results from the formation of vacuoles between the external membrane and the rest of the chloroplast (blebs), by increase in interlamellar spacing and by the formation of vacuoles between the lamellæ. The interlamellar vacuoles form by the lamellæ rounding up and coelescing to enclose the granular interlamellar material. Quantitative results for the volume : osmotic pressure relations, the volume : $p H$ relations, the surface charge, and the apparent free space for potassium chloride show that swelling is an osmotic process. The osmotic gradients arise from (a) a Donnan system associated with the interlamellar material, and (b) from diffusible solutes present in the interlamellar solution. The high values for the apparent free space and the volume: $p \mathrm{H}$ 